\title{
A RADIOATIVIDADE NATURAL DA REGIÃO DE IRECÊ, BA
}

\author{
CLEMIRO FERREIRA*, LYCIA M. MOREIRA-NORDEMANN** e DANIEL J.R. NORDEMANN**
}

\begin{abstract}
NATURAL RADIOACTIVITY OF THE REGION OF IRECÊ, BAHIA STATE, BRAZIL. Scintillometric measurements were performed over an area of about $10.000 \mathrm{~km}^{2}$ in the calcareous region of Irecê (Bahia State, Brazil). Total gamma activity counting rates were found to be between 45 and $80 \mathrm{cps}$, with amean value of $50 \mathrm{cps}$, showing a rather homogeneous environmental total radioactivity. Seventy samples of rocks and soils were collected and their concentration of uranium, thorium and potassium were measured by laboratory gamma-ray spectrometry. At the same time iron and manganese rich concretions were sampled and studied, indicating strong correlation of $\mathrm{MnO}-\mathrm{U}$ and $\mathrm{Fe}_{2} \mathrm{O}_{3}$-Th type. The results obtained were discussed from the point of view of the geochemical behavior of natural radioactive elements and correlated with previous data on underground waters of the region.
\end{abstract}

Keywords: Natural radioactivity, limestones, uranium, thorium, potassium, Irecê, Bahia state, Brazil, scintillometric measurements, gamma-ray spectrometry.

RESUMO Perils de cintilometria cobrindo uma área de $10.000 \mathrm{~km}^{2}$ foram efetuados na região calcária de Irecê, Estado da Bahia. As contagens situam-se entre 45 e $80 \mathrm{cps}$ e o valor médio obtido foi $50 \mathrm{cps}$, revelando assim uma radioatividade total ambiente bastante homogenea. Coletas de 70 amostras de rochas e solos da região foram efetuadas e os seus teores de urânio, tório e potássio foram analisados por espectrometria gama em laboratório. Paralelamente, concreções ricas em Fe e M n foram coletadas e estudadas, tendo sido observadas fortes correlações do tipo $\mathrm{MnO}-\mathrm{U}$ e $\mathrm{Fe}_{2} \mathrm{O}_{3}$-Th. O conjunto de resultados obtidos foi discutido do ponto de vista do comportamento geoquímico dos elementos radioativos estudados, assim como correlacionados com dados anteriormente obtidos em águas subterrâneas da região.

Palavras-chaves: Radiatividade natural, calcários, urânio, tório, potássio, Irecê, Bahia, Brasil, medidas de cintilometria, espectrometria gama.

INTRODUÇÃO Elementos radioativos naturais são encontrados em rochas, e a determinação destes elementos e de seus teores podem fornecer dados adicionais sobre as características destas rochas. Em particular, ${ }^{40} \mathrm{~K},{ }^{232} \mathrm{Th}$ e ${ }^{223} \mathrm{U}$ desempenham um papel predominante no estudo da radioatividade das rochas da crosta terrestre, devido à abundância inicial destes elementos e à ordem de grandeza de suas respectivas meia-vidas, sendo possível detectá-los por espectrometria gama, diretamente, ou através de seus descendentes (Nordemann, 1966). A ocorrência dos elementos radioativos está intimamente correlacionada com a composição mineralógica das rochas. Minerais mais abundantes como o quartzo e os plagioclásios são pobres em elementos radioativos, ao passo que as micas apresentam geralmente altos teores. Minerais secundários, como zircão, apatita, monazita, etc. tam-bém apresentam elevados teores de elementos radioativos, sobretudo de urânio (Cherdyntsev et al. 1971, Le Van Tiet 1975, Moreira-Nordemann 1977). Deste modo, alguns tipos de rochas apresentam uma radioatividade natural mais elevada do que outras.

Em relação às rochas calcárias, estudos anteriores (Nordemann 1966) já demonstraram que estas apresentam em geral baixos teores de elementos radioativos: o potássio é pouco abundante, por não ser um constituinte dos minerais essenciais destas rochas; tão pouco são encontrados em rochas calcárias minerais ricos em urânio e em tório. Por outro lado, a similaridade de comportamento geoquímico entre urânio e tório, normalmente observada em outros tipos de rochas, não é encontrada no caso das rochas sedimentares (Clark et al 1966). O urânio é parcialmente oxidado e passa ao estado hexavalente, produzindo o íon solúvel uranil; o tório é mais encontrado na matéria em suspensão do que em solução, e a pouca quantidade de tório solúvel é rapidamente fixada em minerais secundários. Deste modo, a razão $\mathrm{Th} / \mathrm{U}$ varia lar- gamente, dependendo do local de deposição e de ser o meio oxidante ou redutor.

A radioatividade natural das rochas tem sido objeto de numerosos estudos, tanto no Brasil quanto no exterior, visando aplicações em várias áreas de Geociências, e especialmente em geocronologia (Amaral \& Kawashita 1967, Sighinolfi 1971, Sighinolfi \& Sakai 1977, Ivanovich \& Hamon 1982) e em geoquímica (Moreira-Nordemann 1980, Scott 1982, Iyer et al 1984, Mantovani et al 1985, 1984, Marques et al 1986, Marques et al 1987), e vários estudos de radioatividade de solos têm também sido publicados (Pliler \& Adams 1962, Rosholt et al 1966, Moreira-Nordemann \& Sieffermenn 1979, Szabo \& Rosholt 1982). No entanto, a quase totalidade destes e outros trabalhos se referem à radioatividade de rochas ígneas e metamórficas, e poucos trabalhos foram realizados sobre rochas calcárias ou solos carbonáticos. No Brasil, em particular, a radioatividade deste tipo de rochas e solos não foi objeto de nenhum estudo específico. No entanto, solos carbonáticos são susceptíveis de apresentar fracionamentos isotópicos e desequilíbrio $\mathrm{Th} / \mathrm{U}$ importantes devido à grande reatividade química que caracteriza as matrizes carbonatadas (Dever 1985, Hillaire-Marcel et al 1990).

Neste trabalho são apresentados perfis cintilométricos correspondentes à atividade gama total dos solos e rochas aflorantes da região de Irecê, centro norte do Estado da Bahia, que é constituída essencialmente de metassedimentos carbonáticos. Também são apresentados os teores de potássio, urânio e tório (determinados por espectrometria gama) de rochas, de concreções ricas em óxidos de ferro e manganês, e de solos desta área. Os resultados obtidos são discutidos em função do contexto geológico da região, assim como em função de estudos anteriormente realizados, visando determinar o comportamento desses elementos na sedimentação e na alteração dessas rochas sob condições de clima semi-árido. 


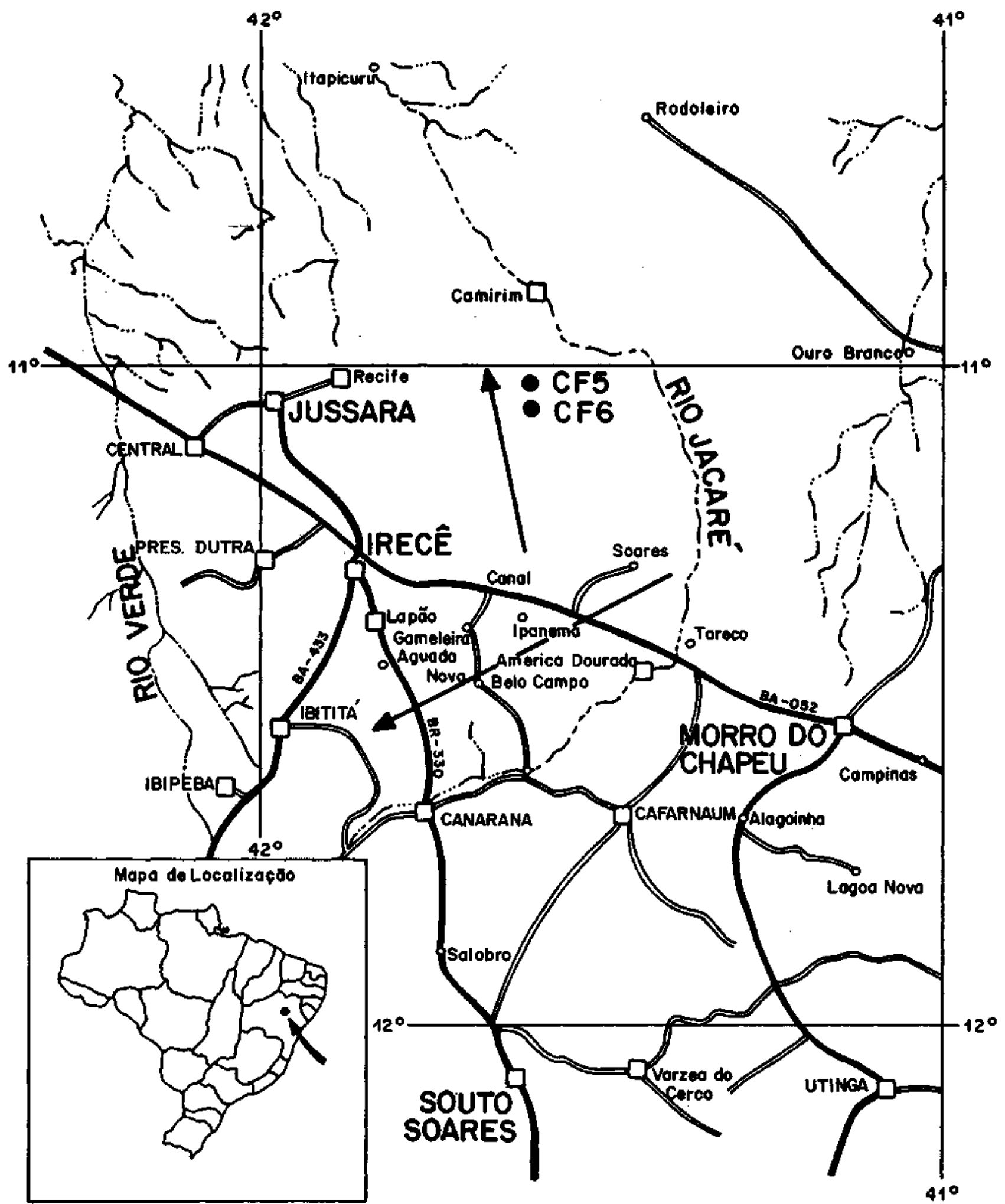

BACIA DE IRECÉ

MAPA DE LOCALIZACĀO

ESCALA $1: 1.000 .000$
ÁREA DO PROJETO $11^{\circ}-12^{\circ} 15^{\prime} S$

$41^{\circ} 20^{\prime}-42^{\circ} 15^{\prime}$

Figura 1 - Localização da área estudada. Perfis de solo CF5 e CF6. As setas indicam o sentido preferencial do fluxo das águas subterrâneas. Figura adaptada de Bonfim et al. (1985)

Figure 1 - Location of the regions investigated. Soil profiles CF5 and CF6. The arrows show the preferential direction of underground water flows. Figure adapted from 
ÁREA DE ESTUDO A extensão da área estudada é de aproximadamente $10000 \mathrm{~km}^{2}$, situada entre $11^{\circ} \mathrm{e} 12^{\circ} 15^{\prime}$ Lat $\mathrm{S}$ e $41^{\circ} 20^{\prime}$ e $42^{\circ} 15^{\prime}$ Long W. Compreende principalmente as bacias do rio Jacaré (ou Vereda) e do rio Verde, ambos de regime intermitente, afluentes da margem direita do rio São Francisco, e abrange alguns municípios, estando a cidade de Irecê situada no centro da região estudada (Fig. 1).

A região de Irecê tem sido objeto de diversos trabalhos, tanto de âmbito regional como local, estes últimos relacionados principalmente às mineralizações. As primeiras referências sobre a região são feitas por Hartt (1870). Seguiram-se numerosos outros trabalhos, e mais recentemente esta área motivou estudos geológicos detalhados (Torquato \& Misi 1977, Misi 1979). Datações foram igualmente efetuadas nas rochas da região (Macedo \& Bonhomme 1984). Uma síntese completa dos trabalhos realizados nesta área é apresentada por Bonfim et al. (1985) que também estudaram em detalhes as mineralizações da região. As águas subterrâneas foram estudadas mediante a utilização de técnicas isotópicas (Siqueira 1978, Bedmar et al. 1980, Gomes \& Cabral 1981).

Segundo Misi (1979), na Bacia de Irecê, as seqüências carbonáticas que constituem o Grupo Una correlacionam-se ao Grupo Bambuí de Minas Gerais e oeste da Bahia; O Grupo Una é representado por duas formações, Formação Salitre e Formação Bebedouro, em nítida discordância erosiva sobre quartzitos do grupo Chapada Diamantina. Diversas unidades litoestratigráfícas são reconhecidas na Formação Salitre, sendo que na região estudada são encontradas as unidades $A_{1}, B$ e $B_{1}$ predominando essencialmente a unidade $A_{1}$. Esta última é formada por calcilutitos maciços, pretos e calcários oolíticos e pisolíticos odorosos. Nas proximidades da base e do topo são freqüentes intercalações de metargilito calcífero. Esta unidade aflora em mais de dois terços da área estudada. Na unidade B observa-se predominantemente a presença de calcários cinzaclaros, muito finos e bem laminados, laminações estas que refletem a existência de finíssimos leitos argilosos bem destacados pela alteração em superfície. Já a unidade $\mathrm{B}_{1}$, caracterizase pela presença de horizontes descontínuos de doloarenitos e dololutitos silicosos, com níveis freqüentemente individualizados de sílex, e que persistem ao longo do mesmo nível estratigráfico.

A composição química e mineralógica da seqüência carbonática é variável e a presença de dolomites e intercalações argilosas são comuns. No entanto, análises petrográficas (Bonfim et al. 1985) e medidas de teores de CaO (Guerra 1986) em rochas da região evidenciaram a monotonia litológica existente na Bacia de Irecê.

Segundo o Mapa Exploratório de Reconhecimento de Solos (EMBRAPA 1973) predominam na região estudada de relevo plano e suavemente ondulado, cambissolos eutróficos de textura média a argilosa. Afloramentos de rocha em regiões topograficamente mais elevadas são comuns. Latosssolos vermelho escuro podem ocorrer ao sul da área estudada, mas sempre associados a cambissolos eutróficos que predominam. A vegetação é representada pela caatinga rala das regiões secas.

Concreções ricas em óxidos de ferro e de manganês foram observadas nos solos e calcários da região, tendo sido igualmente coletadas e analisadas. As concreções ricas em ferro são arredondadas e apresentam coloração marrom avermelhada e superfície externa brilhante. A consistência é dura a moderadamente dura. $\mathrm{O}$ ferro está distribuído de modo mais homogêneo nestas concreções, as quais apresentam teores menos elevados de manganês. Já as concreções mais ricas em manganês são arredondadas, apresentando uma capa mais rica em ferro, provavelmente goethita, sendo que o oxido de manganês encontra-se concentrado no nódulo das mesmas. O diâmetro das concreções varia entre 0,5 e $1,5 \mathrm{~cm}$.

AMOSTRAGEM E METOdOLOGIA A realização de perfis cintilométricos permite não só quantificar o background radioativo de uma dada região como também verificar a existência ou não de homogeneidade do mesmo. Foram realizados 35 perfis totalizando $2390 \mathrm{~km}$ de extensão, utilizando a malha viária primária da região. As variações da atividade radioativa, velocidade do veículo e demais dados de interpretação dos perfis foram anotados em função da quilometragem indicada por um totalizador aferido, com anotações de numerosos pontos de referência geográfica (cidades, rios, pontes, marcos de estrada etc). Sempre que valores anômalos foram registrados (contagens muito superiores ou inferiores ao valor médio), o percurso era repetido e amostras eram coletadas. Os métodos empregados na execução deste trabalho foram previamente desenvolvidos e testados, tendo sido descritos em detalhes em publicações anteriores (Nordemann 1966, Ferreira 1973, Barreto 1974, Ferreira et al. 1979).

O aparelho utilizado foi um cintilômetro SPP3 de fabricação S.R.A.T., munido de um cristal cintilador de iodeto de sódio ativado com tálio, de $38 \times 25 \mathrm{~mm}$, operando a $1 \mathrm{~m}$ de altura (Ferreira et al. 1979). A taxa de contagem integrada pelo aparelho representa o resultado da detecção pelo cristal cintilador da atividade gama ambiente, devida principalmente aos elementos emissores gama naturais presentes na camada superior dos solos e rochas aflorantes, com uma pequena contribuição da radiação de origem cósmica.

As amostras de rochas obtidas foram coletadas em afloramentos: três ocorrem próximo a Irecê, centro da área estudada, seis ao norte e dois ao sul desta cidade. As amostras de solos, em número de 60 , foram coletadas em toda a região, e dois perfis de solo foram realizados a NE de Irecê (Fig. 1).

A determinação dos teores de urânio, tório e potássio nestas amostras foi feita por espectrometria gama em laboratório. A instalação compreende um detector de cintilação munido de um cristal cintilador de iodeto de sódio ativado com tálio, de $100 \times 80 \mathrm{~mm}$, associado a uma fotomultiplicadora com janela de quartzo colocado dentro de uma proteção de ferro $(25 \mathrm{~mm}$ de espessura) e de chumbo (200 $\mathrm{mm}$ de espessura), e um analisador de pulsos Hewlett-Packard de 1024 canais. A calibração em energia foi realizada de modo a se obter $10 \mathrm{keV}$ por canal. Os rendimentos de detecção empregados (Nordemann 1966), adaptados por um dos autores (C.F.), são apresentados na tabela 1. Estes rendimentos são válidos para medidas feitas em $0,800 \mathrm{~kg}$ de amostra moída, contidos em um recipiente de plástico cilíndrico com base de $100 \mathrm{~mm}$ de diâmetro.

Tabela 1 - Rendimentos de deteção (Ferreira 1973 e Ferreira et al. 7979, modificados a partir de Nordemann 1966)

Tablel - Efficiencies of detection (Ferreira 1973 and Ferreira et al. 1979, modified from Nordemann 1966)

\begin{tabular}{|c|c|c|c|}
\hline Energia & $\begin{array}{c}\text { Rádio- } \\
\text { Elemento }\end{array}$ & $\begin{array}{l}\text { Rendimentos } \\
\text { Aparentes }\end{array}$ & $\begin{array}{l}\text { Rendimentos } \\
\text { das Análises }\end{array}$ \\
\hline 583 & Th & \multirow{2}{*}{$\begin{array}{cc}2,0 & \\
& -0,1\end{array}$} & $95 \mathrm{cph} / \mathrm{mg} \mathrm{Th}$ \\
\hline 607 & $\mathrm{U}$ & & $590 \mathrm{cph} / \mathrm{mg}$ Th \\
\hline 1460 & $\mathbf{K} 40$ & $1,73 \pm 15$ & $205 \mathrm{cph} / \mathrm{mg} \mathrm{K}$ \\
\hline 2615 & Th & $0,77 \pm 0,08$ & $39,6 \mathrm{cph} / \mathrm{mg}$ Th \\
\hline
\end{tabular}

A incerteza correspondente a cada medida provém da incerteza sobre o rendimento e a geometria de detecção, e da incerteza devida à estatística de contagem, combinadas quadraticamente. Globalmente as incertezas relativas à série de medidas descritas neste trabalho são da ordem de $25 \%$. Quando 
se considera apenas a comparação dos resultados entre si, as incertezas são menores, e, a depender dos casos, estão compreendidas entre 10 e $15 \%$.

Os teores de ferro e de manganês das concreções encontradas no solo foram determinadas por espectrometria de absorção atômica.

RESULTADOS E DISCUSSÕES Os resultados obtidos para os perfis cintilométricos demonstram aparentemente uma grande homogeneidade no fundo ambiente (background) de radiação gama da região estudada. Os valores obtidos situam-se entre 45 e $80 \mathrm{cps}$ (pulsos por segundo), raramente ultrapassando $60 \mathrm{cps}$, sendo $50 \mathrm{cps}$ o valor médio encontrado. Além de evidenciar esta aparente homogeneidade no fundo ambiente de radiação gama, estes resultados indicam concentrações em elementos radioativos relativamente baixas dos solos e rochas aflorantes. As determinações dos teores de urânio, tório e potássio das rochas e solos, efetuadas em laboratório, são portanto essenciais para confirmar tais resultados e serão discutidas a seguir.

A tabela 2 apresenta as concentrações de urânio, tório e potássio determinadas por espectrometria gama em 70 amostras de solos e rochas calcárias da região. Observa-se que os teores em urânio das rochas calcárias situam-se entre 1,6 e 0,1 ppm, sendo que apenas três das onze amostras analisadas possuem teores superiores à unidade.

Resultados anteriores obtidos em 10 amostras de calcário de várias regiões do globo (Nordemann, 1966) exibiram teores de urânio entre 0 e 6,5 ppm, e teores de tório entre 0 e 5,6 ppm. Segundo Gascoyne (1982), os calcários possuem teores de urânio em torno de $2 \mathrm{ppm}$ e pouco ou nenhum tório (de 0 a 2,4 $\mathrm{ppm}$ ), sendo a relação $\mathrm{Th} / \mathrm{U}$ inferior a 1 . Os calcários de Irecê apresentam razões $\mathrm{Th} / \mathrm{U}$ tanto superiores quanto inferiores à unidade, sendo que as amostras 19, 44 e 46, mais ricas em U, são anormalmente ricas em Th. Os teores de K de algumas destas rochas também são superiores aos anteriormente determinados em calcários de outras regiões, de 0 a 0,25 ppm (Nordemann 1966). Contudo os calcários da região de Irecê apresentam teores de $\mathrm{U}$, Th e $\mathrm{K}$ inferiores aos obtidos em rochas sedimentares (arenitos) do Recôncavo, no Estado da Bahia (Ferreira et al 1979) e teores de U bem inferiores aos valores obtidos em calcários de região semi-árida africana (Hillaire-Marcel et al 1990).

Os teores de $\mathrm{K}$ dos solos são equivalentes aos observados nas rochas, indicando que o $\mathrm{K}$ emigra com o carbonato quando o mesmo é alterado e/ou dissolvido. Porém os teores de Th determinados nos solos desta área são nitidamente superiores aos das rochas

A conhecida e já citada baixa solubilidade do Th é responsável pelo enriquecimento em Th dos solos. Estes resultados

Tabela 2 - Teores de urânio, tório e potássio dos solos e calcários da região de Irecê

Table 2 - Concentrations of uranium, thorium and potassium of soils and limestones of the Irecê region

\begin{tabular}{|c|c|c|c|c|}
\hline Tipo & $\begin{array}{l}\text { Amostra } \\
\text { Número }\end{array}$ & $\underset{(\mathrm{ppm})}{\mathrm{U}}$ & $\begin{array}{c}\text { Th } \\
(\mathrm{ppm})\end{array}$ & $\underset{(\%)}{K}$ \\
\hline Solo & 3 & 1,2 & 5.6 & 0,3 \\
\hline Solo & 4 & 1,6 & 7,9 & 0,6 \\
\hline Solo & 7 & 1,5 & 4,8 & 0,3 \\
\hline Solo & 8 & 0,8 & 8,6 & 0,6 \\
\hline Solo & 9 & 2,4 & 6,2 & 0,5 \\
\hline Solo & 11 & 1,0 & 9,6 & 0.8 \\
\hline Solo & 12 & 1,8 & 10,5 & 0,4 \\
\hline Solo & 13 & 2,1 & 8,4 & 0,6 \\
\hline Solo & 14 & 1,6 & 4,5 & 1,2 \\
\hline Solo & 16 & 1,4 & 9.7 & 0,7 \\
\hline Solo & 17 & 1,3 & 16,1 & 0,7 \\
\hline Solo & 23 & 1,9 & 12,2 & 0,5 \\
\hline Solo & 24 & 1,4 & 19,3 & ind. \\
\hline Solo & 25 & 1,1 & 9,6 & 0,1 \\
\hline Solo & 27 & 0,2 & 4,0 & 0,3 \\
\hline Solo & 28 & 0,8 & 11,7 & 0,2 \\
\hline Solo & 30 & 0,8 & 10,3 & 0,1 \\
\hline Solo & 31 & 0,5 & 6,7 & 0,5 \\
\hline Solo & 33 & 0,1 & 16,3 & 0,6 \\
\hline Solo & 34 & 1,5 & 9,3 & 0,7 \\
\hline Solo & 35 & 1,7 & 8,2 & 1,1 \\
\hline Solo & 36 & 1,1 & 11,5 & 1,1 \\
\hline Solo & 38 & 1,4 & 9,8 & 0,4 \\
\hline Solo & 39 & 0,6 & 10,2 & 0,2 \\
\hline Solo & 40 & 1,2 & 6,9 & 0,1 \\
\hline Solo & 42 & 1,0 & 6,0 & 0,1 \\
\hline Solo & 43 & 1,3 & 5,2 & 1,8 \\
\hline Solo & 45 & 0,6 & 7,9 & 0,3 \\
\hline Solo & 47 & 1,5 & 0,4 & 1,0 \\
\hline Solo & 48 & 2,0 & 7,5 & 0,6 \\
\hline Solo & 49 & 0,6 & 7,4 & 0,3 \\
\hline Solo & 50 & 1,1 & 7.1 & 0.4 \\
\hline Solo & 51 & 1,2 & 8,1 & 0,5 \\
\hline Solo & 52 & 1,0 & 7,2 & 0,3 \\
\hline Solo & 53 & 0,8 & 11,0 & 0,3 \\
\hline
\end{tabular}

\begin{tabular}{l|c|c|c|c}
\hline \multicolumn{1}{c|}{ Tipo } & $\begin{array}{c}\text { Amostra } \\
\text { Número }\end{array}$ & $\begin{array}{c}\text { U } \\
\text { (ppm) }\end{array}$ & $\begin{array}{c}\text { Th } \\
\text { (ppm) }\end{array}$ & $\begin{array}{c}\mathbf{K} \\
(\%)\end{array}$ \\
\hline Solo & 54 & 1,3 & 9,3 & 0,7 \\
Solo & 55 & 0,9 & 9,1 & 0,2 \\
Solo & 56 & 0,7 & 6,4 & 0,0 \\
Solo & 57 & 0,6 & 10,7 & 0,5 \\
Solo & 58 & 0,3 & 11,4 & 0,6 \\
Solo & 59 & 0,4 & 11,4 & 0,4 \\
Solo & 60 & 1,5 & 12,7 & 0,6 \\
Solo & 61 & 0,7 & 15,0 & 0,4 \\
Solo & 62 & 0,9 & 10,5 & 0,2 \\
Solo & 63 & 1,2 & 18,5 & 0,2 \\
Solo & 64 & 0,7 & 7,5 & 1,3 \\
Solo & 65 & 0,0 & 12,5 & 0,1 \\
Solo & 66 & 1,2 & 13,7 & 0,5 \\
Solo & 67 & 1,6 & 19,5 & 0,1 \\
Solo & 68 & 0,9 & 22,0 & 0,1 \\
Solo & 69 & 1,8 & 15,2 & 0,5 \\
Solo & 71 & 1,4 & 11,0 & 1,6 \\
Solo & 72 & 1,1 & 11,5 & 0,1 \\
Solo & 74 & $\mathbf{i n d .}$ & 10,0 & 0,0 \\
Solo & 75 & 1,2 & 8,6 & 0,1 \\
Solo & 76 & 1,4 & 12,2 & 0,1 \\
Solo & 77 & 0,5 & 12,9 & 0,1 \\
Solo & 78 & 0,9 & 7,0 & 0,3 \\
Rocha calcária & 1 & 0,9 & 0,3 & 0,3 \\
Rocha calcária & 15 & 0,3 & 0,3 & 0,3 \\
Rocha calcária & 19 & 1,2 & 5,2 & 1,9 \\
Rocha calcária & 20 & 0,7 & 0,3 & 0,1 \\
Rocha calcária & 26 & 0,1 & 0,0 & ind. \\
Rocha calcária & 29 & 0,4 & ind. & 0,1 \\
Rocha calcária & 32 & 0,2 & 0,5 & 0,1 \\
Rocha calcária & 37 & 0,9 & 0,3 & 0,8 \\
Rocha calcária & 41 & 0,5 & 0,9 & 0,3 \\
Rocha calcária & 44 & 1,1 & 7,7 & 3,7 \\
Rocha calcária & 46 & 1,6 & 10,8 & 0,4 \\
\hline ind.: inferior ao limite de deteção & & & \\
& & & &
\end{tabular}


são comprovados através de dados apresentados na tabela 3, correspondente a dois perfis de solos efetuados a NE de Irecê (Fig. 1). No perfil CF-6, observa-se uma nítida acumulação de Th no horizonte superficial, assim como nos horizontes $\mathrm{A}_{3} \mathrm{e} \mathrm{B}$ do perfil CF-5. Já no horizonte A, deste último, esta acumulação é menos nítida devido ao efeito de erosão a que este deve estar submetido, pois corresponde a uma cota mais elevada que a do perfil CF-6.

Tabela 3 - Teores de urânio, tório e potássio obtidos em dois perfis de solos da região de Irecê. Perfil CFI-5: Cambissolo eutrófico, C carbonático, A fraco, relevo plano, fase caatinga hiperxerófita. Perfil CFI-6: Bruno cálcico, eutrófico, A fraco, relevo suave ondulado, fase caatinga hipoxerófita. $C_{1}, C_{2}$ e $C_{3}$ são diferentes profundidades da rocha alterada Table 3 - Concentrations of uranium, thorium and potassium in two soil profiles of the Irecê region. Profile CFI-5: Eutrophic Cambisol, C carbonatic, flat relief, caatinga, hyper xerophytic. Profile CFI-6: Calcic brown, eutrophic, weak A horizon, slightly hilly topography, caatinga, hypo xerophytic vegetation. $\mathrm{C}_{1}, \mathrm{C}_{2}$ and $\mathrm{C}_{3}$ are different levels of the weathered rock

CFI-5

\begin{tabular}{c|c|c|c|c|}
\hline Horizonte & $\begin{array}{c}\text { Profundidade } \\
(\mathrm{cm})\end{array}$ & $\begin{array}{c}\mathrm{U} \\
(\mathrm{ppm})\end{array}$ & $\begin{array}{c}\mathrm{Th} \\
(\mathrm{ppm})\end{array}$ & $\begin{array}{c}\mathrm{K} \\
(\%)\end{array}$ \\
\hline $\mathrm{A} 1$ & $0-10$ & 1,5 & 4,7 & 1,1 \\
\hline $\mathrm{A} 3$ & $10-30$ & 1,7 & 5,4 & 1,1 \\
\hline $\mathrm{B}$ & $30-60$ & 2,5 & 5,4 & 0,9 \\
\hline $\mathrm{C}$ & $90-110$ & 0,6 & 3,9 & 0,5 \\
\hline
\end{tabular}

CFI-6

\begin{tabular}{c|c|c|c|c|}
\hline Horizonte & $\begin{array}{c}\text { Profundidade } \\
(\mathrm{cm})\end{array}$ & $\begin{array}{c}\mathrm{U} \\
(\mathrm{ppm})\end{array}$ & $\begin{array}{c}\text { Th } \\
(\mathrm{ppm})\end{array}$ & $\begin{array}{c}\mathrm{K} \\
(\%)\end{array}$ \\
\hline $\mathrm{A}$ & $0-30$ & 1,1 & 8,5 & 0,9 \\
\hline $\mathrm{C} 1$ & $40-70$ & 1,5 & 1,8 & 0,6 \\
\hline $\mathrm{C} 2$ & $80-105$ & 0,7 & 3,2 & 0,5 \\
\hline $\mathrm{C} 3$ & $120-145$ & 0,2 & 3,5 & 0,4 \\
\hline
\end{tabular}

Os teores de U dos solos são também de um modo geral mais elevados que os observados nas rochas. $\mathrm{O} U$ é um elemento solúvel em águas naturais e em formações calcárias; complexos solúveis são também formados (Gascoyne 1982) com fosfatos, sulfatos e fluoretos, que são abundantes na região de Irecê. Deste modo, o enriquecimento do U observado nos solos pode ser explicado por duas hipóteses: a. a "acumulação" é aparente e resulta da alteração isovolume observada na região (Riche et al 1982); b. Está havendo "transferência" vertical de U nos perfis de solo.

Estes resultados podem ser melhor discutidos observando-se os teores em urânio obtidos nas amostras dos dois perfis de solo efetuados (Tab. 3): observa-se que os teores de urânio são nitidamente mais elevados nos horizontes superiores dos perfis. Tal fato foi anteriormente observado em solos de outras regiões do globo. Pliler e Adams (1962) observaram em perfis de solos do Colorado (Estados Unidos), teores de urânio quatro vezes superiores nos horizontes mais alterados que em rochas sãs. Solos derivados de calcários também apresentam teores de U superiores aos da rocha mãe (Hillaire-Marcel et al. 1990). Do mesmo modo, foi constatado (Rosholt et al. 1966, Hansen \& Stout 1968, Moreira-Nordemann \& Sieffermann 1979) que o urânio é lixiviado em profundidade nos perfis de solo, tendendo a se concentrar nos horizontes superiores, o que determina que as concentrações de urânio são tanto mais elevadas quanto maior é a distância da rocha mãe. Esta "acumulação" é aparente uma vez que ela provém da fixação do urânio residual (e não lixiviado) da rocha mãe pelas argilas. À alteração da rocha segue-se uma perda de matéria que é lixiviada, e o urânio residual não solubilizado tende a se "acumular" no solo, apenas porque este fica desprovido de uma parte dos seus constituintes iniciais. Altos teores de urânio podem ser encontrados no topo dos perfis de solo sem dúvida, graças à presença das argilas de alteração. Infelizmente, análises de granulometria das amostras destes perfis não estão disponíveis, porém, segundo estudos de distribuição de urânio nos solos (Moreira-Nordemann 1977), sabe-se que as argilas e os minerais pesados residuais das rochas são os principais responsáveis pelas concentrações em urânio observadas nos solos. No presente caso, as rochas calcárias da região sendo pobres em minerais pesados ricos em urânio, possivelmente todo o urânio residual deve estar concentrado nas argilas. Em particular, nota-se um nítido aumento em urânio no horizonte B do perfil CF-5, e é provável que a acumulação de urânio corresponda também a um maior teor de argila neste horizonte.

Por outro lado (hipótese b), é possível que os teores mais elevados de U no horizonte B do perfil CF-5 e C, do CF-6 correspondam a uma migração do U: em regiões calcárias de clima semi-árido, onde a evaporação é intensa, o $\mathrm{Ca}$ e o $\mathrm{Mg}$ seguem o movimento descendente da água na estação chuvosa e o movimento ascendente durante a estação seca (Boyer 1971), e neste caso, o U estaria se comportando como o $\mathrm{Ca}$ e o $\mathrm{Mg}$. Outra possibilidade seria estar ocorrendo uma precipitação de U, acompanhando uma precipitação de calcita, tal como foi constatada anteriormente (Hillaire-Marcel et al 1990) em região calcária semi-árida da Africa. Datações a diferentes níveis estratigráficos seriam necessárias para confirmar esta última alternativa.

Nódulos carbonáticos e concreções são facilmente encontrados em formações pedogenéticas carbonáticas de regiões semi-áridas (Boyer 1971, Schwarcz et al 1981).

$\mathrm{Na}$ tabela 4, estão apresentados os teores de U, Th, K, $\mathrm{MnO}$ e $\mathrm{Fe}_{2} \mathrm{O}_{3}$ determinados em concreções (nódulos) encontradas em solos e rochas da região. Observa-se que estas concreções apresentam baixos teores de potássio. Por outro lado, algumas amostras são anormalmente ricas em urânio e tório. Comparando-se os teores de $\mathrm{U}$ e $\mathrm{MnO}$, verifica-se que há uma correlação positiva entre estes resultados: amostras com teores anormalmente elevados em MnO correspondem a teores também elevados em urânio. Do mesmo modo, amostras com altas concentrações de $\mathrm{Fe}_{2} \mathrm{O}_{3}$ apresentam também altas concentrações em tório. A partir destes resultados, pode-se então constatar que, nestas concreções em particular, há uma forte associação U-MnO e Th- $-\mathrm{Fe}_{2} \mathrm{O}_{3}$. Baseando-se então nos resultados da tabela 4, determinou-se os coeficientes de correlação linear entre os logaritmos dos teores dos elementos e óxidos tomados dois a dois, cujos resultados são apresentados na tabela 5. A partir destes resultados, observa-se o agrupamento característico dos elementos analisados em dois grupos de afinidade geoquímica, de um lado $\mathrm{Mn}, \mathrm{K}$ e U, e do outro lado Th e Fe; Os elementos são fortemente correlacionados entre si dentro de cada grupo $(\mathrm{r}=0,98 ; 0,91 ; 0,89$ para o primeiro grupo e 0,77 para o segundo grupo) e fortemente anticorrelacionados entre os dois grupos $(\mathrm{r}=-0,91 ;-0,90 ;-0,88 ;-0,84$; $-0,78 ;-0,91)$.

A título de comparação são apresentados na tabela 6 os coeficientes de correlação linear entre os logaritmos dos teores dos mesmos elementos para 500 medidas feitas em rochas sedimentares da Bacia de Paris, França (Bienner et al 1968). Pode-se observar em primeiro lugar que os coeficientes de correlação obtidos no presente trabalho (Tab. 5) são, nitidamente maiores em valor absoluto, isto é mais perto de $1 \mathrm{ou}$ de -1 , do que no caso da Bacia de Paris (Tab. 6). Para as concreções da Bacia de Irecê, correlações (ou anticorrelações) são mais fortes devido à maior homogeneidade dos processos 
Tabela 4 - Teores de urânio, tório, potássio, $\mathrm{MnO}$ e $\mathrm{Fe}_{2} \mathrm{O}_{3}$ em concreções encontradas nos solos da região de Irecê

Table 4 - Concentrations of uranium, thorium, potassium, $\mathrm{MnO}$ and $\mathrm{Fe}_{2} \mathrm{O}_{3}$ in concretions found in soils of the Irecê region

\begin{tabular}{c|c|c|c|c|c}
\hline $\begin{array}{c}\text { Amostra } \\
\text { número }\end{array}$ & $\begin{array}{c}\mathrm{U} \\
(\mathrm{ppm})\end{array}$ & $\begin{array}{c}\mathrm{Th} \\
(\mathrm{ppm})\end{array}$ & $\begin{array}{c}\mathrm{K} \\
(\%)\end{array}$ & $\begin{array}{c}\mathrm{MnO} \\
(\%)\end{array}$ & $\begin{array}{c}\mathrm{Fe}_{2} \mathrm{O}_{2} \\
(\%)\end{array}$ \\
\hline 1-C & 6,6 & 3,6 & 0,7 & 10,2 & 23,2 \\
\hline 2-C & 4,1 & 4,3 & 0,8 & 9,0 & 25,0 \\
\hline 3-C & 0,8 & 14,3 & 0,3 & 0,6 & 33,1 \\
\hline 4-C & 0,9 & 13,1 & 0,5 & 0,8 & 30,8 \\
\hline 5-C & 1,0 & 13,5 & 0,4 & 0,9 & 31,2 \\
\hline 6-C & 4,6 & 7,9 & 0,9 & 9,2 & 20,4 \\
\hline $7-\mathrm{C}$ & 5,1 & 3,3 & 0,7 & 9,7 & 24,6 \\
\hline 8-C & 0,6 & 12,9 & 0,3 & 0,7 & 29,8 \\
\hline 9-C & 0,8 & 12,4 & 0,5 & 0,5 & 30,0 \\
\hline 10-C & 5,8 & 6,9 & 0,7 & 10,5 & 25,3 \\
\hline 11-C & 5,2 & 6,3 & 0,9 & 10,3 & 22,8 \\
\hline $12-\mathrm{C}$ & 1,0 & 15,6 & 0,4 & 0,5 & 39,4 \\
\hline 10 & 7,2 & 3,8 & 0,7 & 10,6 & 24,7 \\
\hline 18 & 1,0 & 13,3 & 0,3 & 0,7 & 32,5 \\
\hline
\end{tabular}

geoquímicos em decorrência da menor extensão geográfica e sobretudo, da menor diversificação estratigráfica em relação à Bacia de Paris. Vale salientar que os coeficientes de correlação linear entre logaritmos de teores de elementos analisados podem representar uma ferramenta poderosa no estudo das associações geoquímicas nas unidades estratigráficas de rochas sedimentares. Porém as associações características entre elementos são melhor evidenciadas quando os coeficientes de correlação são calculados para uma unidade estratigráfica e não para uma região estratigraficamente heterogênea. Estas considerações explicam os baixos valores dos coeficientes de correlação obtidos por Bienner et al. (1968) no caso da Bacia de Paris (Tab. 6).

Um estudo anteriormente efetuado (Gomes \& Cabral 1981) utilizou isótopos de urânio, como traçadores, para verificar áreas de recarga do aqüífero da região. Medidas de teores de urânio foram efetuadas em 39 poços nesta mesma área em estudo, utilizando-se o método da espectrometria alfa. A área

Tabela 5 - Coeficientes de correlação linear entre os logaritmos das concentrações medidas em 14 amostras de concreções da Bacia de Irecê

Table 5 - Coefficients of linear corrrelation between logarithms of the concentrations measured in 14 samples of concretions found in soils of the Irecê region

\begin{tabular}{c|c|c|c|c}
\cline { 2 - 5 } & $\mathrm{Mn}$ & $\mathrm{Fe}$ & $\mathrm{K}$ & $\mathrm{Th}$ \\
\hline $\mathbf{U}$ & 0,98 & $-0,84$ & 0,89 & $-0,91$ \\
\hline $\mathrm{Th}$ & $-0,91$ & 0,77 & $-0,78$ & \\
\hline $\mathrm{K}$ & 0,91 & $-0,88$ & & \\
\hline $\mathrm{Fe}$ & $-0,90$ & & & \\
\hline
\end{tabular}

Tabela 6 - Coeficientes de correlação linear entre os logarítmos das concentrações medidas em 500 amostras de rochas da Bacia de Paris, França (Bienner et al. 1968) Table 6 - Coefficients of linear corrrelation between logarithms of the concentrations measured in 500 samples of rocks from the Paris Basin (Bienner et al. 1968)

\begin{tabular}{c|c|c|c|c}
\cline { 2 - 5 } & $\mathrm{Mn}$ & $\mathrm{Fe}$ & $\mathrm{K}$ & $\mathrm{Th}$ \\
\hline $\mathrm{U}$ & 0,38 & 0,52 & 0,40 & 0,39 \\
\hline $\mathrm{Th}$ & 0,12 & 0,62 & 0,62 & \\
\hline $\mathrm{K}$ & 0,44 & 0,79 & & \\
\hline Fe & 0,65 & & & \\
\hline
\end{tabular}

de recarga foi definida e localizada onde os excessos de U-234 são baixos. As setas na figura 1 indicam o sentido preferencial dos fluxos de água subterrânea da região. Dentre 39 poçãos analisados, cinco deles apresentaram teores de U entre 4 e 9 ppb. Posteriormente, análises em outros poços ao NE de Irecê (Ferreira, 1983) revelaram teores de U entre 7 e 15 ppb e razões U234/U238 entre 4 e 8 . Outro estudo utilizando isótopos $\left({ }^{18} \mathrm{O} /{ }^{16} \mathrm{O}\right)$ foi efetuado na região (Bedmar et al 1980) e os resultados obtidos concordam com os do trabalho anteriormente citado (Gomes \& Cabral 1981) sugerindo também que o tempo de renovação das águas subterrâneas em torno de Irecê é de 67 anos, superior aos encontrados para os poços situados ao sul da região estudada (sul de Irecê) que seria em torno de 22 anos. Esta zona ao redor de Irecê apresenta também (Guerra 1986) os índices pluviométricos mais baixos. Por outro lado (Siqueira 1978, Guerra 1986), análises efetuadas em vários poços de toda a região demonstraram que não existe homogeneidade química ou isotópica no sistema aqüífero, o que é evidenciado pela tendência que apresentam estas águas de formarem "grupos" com caraterísticas similares, e apresentando diferentes graus de salinidade.

Um experimento de lixiviação de rochas efetuado anteriormente em laboratório (Moreira-Nordemann \& Lalou 1972) demonstrou que o teor de urânio das águas de lixiviação é função do teor de urânio das rochas lixiviadas e do grau de alteração das mesmas; demonstrou também que o tempo de contato entre a rocha e a água não parece ser preponderante para a lixiviação do urânio da rocha pela água, e que águas com teores de sais mais elevados parecem mais eficazes (talvez devido à maior concentração iônica e/ou a um poder de complexação mais elevado) para extrair urânio das rochas por lixiviação. No caso da região de Irecê, considerando-se que a composição química das águas é diretamente influenciada pela dissolução dos calcários, e que estes, como já foi demonstrado, são pobres em urânio, não é possível portanto justificar deste modo os teores elevados em urânio encontrados em alguns poços. Por outro lado, também, não é possível justificar a presença de altas concentrações de urânio nas águas, só pela lixiviação do urânio dos solos. O que pode ser sugerido é que os poços cujas águas apresentam teores em urânio elevados são aqueles onde concreç̃es ricas em urânio e MnO acham-se presentes. Esta hipótese baseia-se no fato de que em um dos poços perfurados na região pela CERB, em cujas águas foi determinado um teor em urânio anormalmente elevado, foi constatada a presença de granules alaranjados a marrom escuros, de aspecto ferruginoso, semelhantes às concreções aqui analisadas. Infelizmente, apenas foi possível obter a descrição litológica detalhada de 6 poços da região, sendo que dentre estes apenas em um foi constatada a presença de tais concreções e o correspondente elevado teor em urânio. Os outros cinco poços apresentam baixo teor de urânio e ausência de concreções. O urânio seria assim "concentrado" nestas águas devido a uma 
ação mais eficaz de águas mais salinizadas na dissolução das concreções ricas em urânio e manganês.

O Th, por outro lado, não deve estar presente em solução nestas águas, pois o $\mathrm{pH}$ das mesmas se acha situado entre 6,3 e 7,9 (Siqueira 1978).

CONCLUSÕES As rochas calcárias do Grupo Una e os solos da região de Irecê (Bahia) apesentam de um modo geral baixos teores de urânio. Tanto os perfis cintilométricos quanto as medidas realizadas por espectrometria gama confirmam tal fato. Os teores de tório são relativamente elevados. Os teores de potássio obtidos em rochas e solos são equivalentes.

Observa-se um enriquecimento em elementos radioativos nos perfis de solo, havendo urna "concentração" destes elementos no material de alteração, certamente devido à conhecida fraca solubilidade do tório e no caso do urânio, seja devido à absorção deste elemento pelas argilas de alteração, seja devido a um processo de migração deste elemento nos perfis de solo.

Altos teores de urânio foram determinados em amostras de concreções ferruginosas, sendo estes resultados sempre associados a elevados teores de oxido de manganês. Por outro lado, teores elevados de tório foram constatados em amostras de concreções cujos teores em óxidos de ferro eram também mais elevados. Embora o número de amostras para as quais os teores de $\mathrm{K}, \mathrm{Mn}, \mathrm{Fe}$, U e Th foram determinados, seja relativamente pequeno, foi feita uma análise dos coeficientes de correlação linear entre os logaritmos dos teores dos elementos tomados dois a dois. Os resultados indicaram uma separação dos elementos em dois grupos: $\mathrm{K}, \mathrm{Mn}$ e U de um lado e Fe e Th do outro, com fortes correlações entre os elementos de cada grupo e fortes anticorrelações entre os elementos de grupos diferentes.

Teores anormalmente elevados de urânio em águas subterrâneas da região foram anteriormente constatados, e sugerese a hipótese de que estes altos teores de urânio em alguns dos poços subterrâneos tenham como origem a dissolução de concreções também anormalmente ricas em urânio.

Em futuras pesquisas feitas com a mesma metodologia experimental, será necessário determinar os coeficientes de correlação entre os teores de um número maior de amostras a fim de investigar os agrupamentos de afinidade geoquímica e discriminar, se for o caso, vários processos geoquímicos responsáveis pelas distribuições das concentrações observadas.

Agradecimentos Os autores agradecem a valiosa colaboração do pedólogo Prof. Joaquim Júlio de Oliveira, do Instituto de Geociências da UFBa, nos trabalhos de campo e nas discussões de caráter pedológico sobre este estudo. Os autores agradecem também aos revisores pelas sugestões apresentadas.

\section{REFERÊNCIAS BIBLIOGRÁFICAS}

AMARAL, G. \& KAWASHITA, K. 1967. Determinação da idade do Grupo Bambuí pelo método Rb-Sr. In: CONOR. BRAS. GEOL., 21. Curitiba, 1967. Anais... Curitiba, SBG. p. 214-217.

BARRETTO, P.T. 1974. Utilização de Métodos Nucleares Geofísicos no Estudo dos Jazimentos de Apatita de Gavião e Ouro da Serra de Jacobina - BA. Salvador. (Dissertação de Mestrado, PPPG-UFBa)

BEDMAR, A.P.; SILVA, A.B.; JARDIM, F.G.; OLIVEIRA. L.B. 1980 Contribuição de diversas técnicas isotópicas no estudo do aqüífero cárstico da região central da Bahia (Irecê-Itaquara). Rev. Bras. Geoc., 10:103-116.

BffiNNER, E; JECHOWSKY, B.; PELET, R.; TISSOT, B. 1968. Abondance et repartition de certains elements dans les formations sédimentaires du bassin de Paris. In: AHRENS, L. H. ed. Origin and Distribution of the Elements, L. H. Ahrens Editor, Pergamon Press. p. 1039-1063.

BONFIM, L.F.C.; ROCH, A.J.D.; PEDREIRA, A.J.; MORAIS, J.C., P; GUIMARES, J.T.; TESCH, N.A. 1985. Projeto Bacia de Irecê. Salvador, CPRM (Relatório Final).

BOYER, J. 1971. Propriedades dos Solos e Fertilidade. Salvador, UFBa. 196 p. (Programa de Textos Didáticos 40).

CHERDYNTSEV, V. V. 1971. Uranium 234. Translated from Russian. Jerusalem, Israel program for Scientific Translations. $234 \mathrm{p}$

CLARK, S.P., Jr.; PETERMAN, Z.E.; HEIER, K.S. 1966. Abundances of uranium, thorium and potassium, in handbook of Physical constants, Geol. Sac. Am. Memoirs, 97:521-541. (Sec. 24)

DEVER, L. 1985. Approches Chimiques et Isotopiques des Interactions Fluides-Matrice en Zone non Saturée Carbonatée. France. (These Doc. d'Etat, Univ. Paris Sud. France).

EMBRAPA. 1973. Mapa Exploratório de Reconhecimento de Solos. Salvador, Secretaria de Agricultura/B A

FERREIRA, C. 1973. Espectrometria Gama de Campo: Determinação das Condições de Detecção: Aplicação ao Mapeamento de uma Jazida de Apatita. Salvador. (Tese de Mestrado, PPPG/UFBa).

FERREIRA, C. 1983. Distribuição de urânio em solos e rochas da região do aqüífero Bambuí. In: Seminário sobre Pesquisas em Andamento na UFBa. Salvador, UFBa,

FERREIRA, C.; BARRETO, P.T.; TORQUATO, J.F. 1979. Reconhecimento gamamétrico da região central da Bahia e da Bacia do Recôncavo. Rev. Bras. Geoc., 9:249-265.

GASCOYNE, M. 1982. Geochemistry of the actinides and their daughters. In: WANOVITCH, M.; HARMON, R.S. Uranium Series Disequilibrium Application to Environmental Problems. Oxford, Oxford Science Publications, Clarendon Press, p. 33-52.

GOMES, R.W. M. \& CABRAL, F.C.F. 1981. Uso de isótopos naturais do urânio no estudo das águas subterrâneas de aqüífero calcário Bambui (BA). Rev. Bras. Geoc., 11:179-184.

GUERRA, A.M. 1986.0 sistema hidrogeológico dos carstes Bambuí na região de Irecê, BA. Rev. Águas Subterrâneas, 10:49-72.

HANSEN, R.O. \& STOUT, RR. 1968. Isotopic distribution of uranium and thorium in soils. Soil Sci., 105:44-50.

HARTT, C.F. 1870. Geologia e Geografia Física do Brasil. Trad. E.S. Mendonça e E. Dolianiti, 1941. (Publicação original em Boston 1870)
HILLAIRE-MARCEL, C.; VALLIERES, S.; GHALELE, B.; MARECHAL, J.C. 1990. Desequilibres Th/U dans les sois carbonates en climat subaride; Estimation des flux d'uranium et vitesse d'erosion. Le cas du Bassin de Palmyre (Syrie). C. R. Acad. Sci., 311(Série II):233-238.

IVANOVICH, M. \& HARMON, R. S. 1982. Uranium Series Disequilibrium. Applications to Environmental Problems. Oxford, Clarendon Press. 571 p.

IYER, S.S. CHOUDHURI, A.; VASCONCELLOS, M.B.A.; CORDANI, U.G. 1984. Radioactive element distribution in the Archean granulite terrane of Jequié - Bahia, Brazil. Contrib. Mineral. Petrol., 85:224-243.

LE VAN TIET. 1975. Géochimie de L'Uranium et du Thorium dans les Granitoides et les Formations Associées de la Montagne Bourbonnaise (Massif Central Francois). Liaisons Possibles avec les Mineralisations Uranifères des Bois Noirs. Lorraine. França. (These, Inst Nat. Polytecnn).

MACEDO, M. H. F. \& BONHOMME, M. G. 1984. Contribuição à cronoestatigrafia das Formações Caboclo, Bebedouro e Salitre da Chapada Diamantina (Ba) pelos métodos Rb-Sr e K-Ar. Rev. Bras. Geoc. 14(3): 153-163.

MANTOVANI, M.S.M.; MARQUES, L.S.; SOUSA, M.A.; ATALLA, L.T.; CrVETTA, L.; INNOCENT!, F. 1985. Trace element and strontium isotope constraints on the origin and evolution of Parará continental flood basalts of Santa Catarina State (Southern Brazil). J. Petrol. 26:187-209.

MARQUES, L.S.; MOLINA, E.G.; MELFI, A.J.; VASCONCELLOS, M.B.A 1987. Determinação de U e Th por meio de técnicas de ativação neutrônica: aplicação à análise de rochas vulcânicas da Bacia do Paraná. In: ENCONTRO REGIONAL DE GEOFÍSICA, 2. Salvador, 1987. Resumos..., Salvador, SBGf. p 29-30.

MARQUES, L.S.; MOLINA, B.C.; VASCONCELLOS, M.B.A.; MELFI, A.J. 1986. Distribuição de U e Th nas rochas vulcânicas da Bacia do Paraná. In: CONG. BRAS. GEOL., 34. Goiânia, 1986. Resumos... Goiânia, SBG. p. 193-194.

MISI, A. 1979. O Grupo Bambuí no Estado da Bahia. Salvador, SME/BA. v. 1. p. 119-154.

MOREIRA-NORDEMANN, L. M. 1977. Etude de la Vitesse d'Alteration des Roches au Moyen de V Uranium Utilise comme Traceur Naturel: Application à deux Bassins du Nord-Est du Brésil. France. (These Doct., d'Etat, Univ.de Paris).

MOREIRA-NORDEMANN, L. M. 1980. Use of $U^{234} / \mathrm{U}^{238}$ Disequilibrium in Measuring Chemical Weathering Rate of Rocks. Geochim. Cosmochim. Acta., 44:103-108.

MOREIRA-NORDEMANN, L. M. 1984. Salinity and Chemical Weathering Rate of Rocks in a Semi-Arid Regiões. J. Hydrol, 71:131-147.

MOREIRA-NORDEMANN, L.M. \& LALOU, C. 1972. Etude experimental du rapport $\mathrm{U}^{234} / \mathrm{U}^{238}$ dans les eaux naturelles ayant traverse différents types de roches. An. Acad. Bras. Cienc. 44(1):12-18.

MOREIRA-NORDEMANN, L. M. \& SffiFFERMANN, G. 1979. Distribution of uranium in soil profiles of Bahia State, Brazil. Soil Sci., 127:275-280.

NORDEMANN, D. 1966. Emissions Gamma de Quelques Meteorites et Roches Terrestres: Evaluation de la Radioactivite du Sol Lunaire. France. (These Doct. d'Etat, Univ. de Paris). (Rapport CEA-R3017). 
PLILER, R. \& ADAMS, J.A.S. 1962. The distribution of thorium and uranium in a Pennsylvanian weathering profile. Geochim. Cosmochim. Acta 26:1137-1146.

RICHE, G ; RAMBAUD, D.; RIERA, M. 1982. Etude morphologique d'un encroutement calcaire, region d'Irece, Bahia, Brésil. Cah. O.R.S.T.O.M., 19(3):257-270. (Ser. Pedol.).

ROSHOLT, J.N.; DOE, B.R.; TATSUMOTO M. 1966. Evolution of the isotopic compositon of uranium and thorium in soil profiles. Geol. Soc. Amer Bull, 77:987-1004

SCHWARCZ, M.; GASCOYNE, M.; HARMON, R. S. 1982. Applications of U-Series dating to problems of quaternary climate. In: IVANOV1CH, M. \& HARMON, R. S. 1982. Uranium Series Disequilibrium. Applications to Environmental Problems. Oxford, Clarendon Press. $571 \mathrm{p}$.

SCOTT, MR 1982. The Chemistry of U- and Th-Series Nuclides in Rivers. In: 1VANOVICH, M. \& HARMON, R. S. 1982. Uranium Series Disequilibrium. Applications to Environmental Problems. Oxford. Clarendon Press. $571 \mathrm{p}$.

SHIGHINOLFI, G.P. 1971. Investigations into the deep crustal levels: fractionating effects and geochemical trend to high grade metamorphism Geochim. Cosmochim. Acta, 35:1005-1021.
SHIGHINOLFI, G.P. \& SAKAI, T. 1977. Uranium and Thorium in Archean Granulite Facies Terrains of Bahia (Brazil). Geochim. J. 11:33-39.

SIQUEIRA, A.F. 1978. O Uso dos Dados Isotópicos e Geoquímicos Como Indicadores de Origem das Aguas e Sais Dissolvidos no Aqüífero Calcário Bambuí, Irecê, Ba. Salvador. (Dissertação de Mestrado, PPPG/ UFBa).

SZABO, B.J. \& ROSHOLT, J.N. 1982. Superficial continental sediments. In: 1VANOVITCH, M.; HARMON, R. S. Uranium Series Disequilibrium; Application to Environmental Problems. Oxford, Clarendon Press. p. 246-262.

TORQUATO, J.R.F. \& MISI, A. 1977. Medidas isotópicas de carbono e oxigênio em carbonates do Grupo Bambuí, na região centro-oeste do Estado da Bahia. Rev. Bras. Geoc., 7(1): 14-24.

MANUSCRITO A671

Recebido em 10 de setembro de 1990 Revisão do autor de 18 de marco de 1992 Revisão aceita em 10 de abril de 1992 